\section{0 processo de declínio da Unasul: causas e consequências para 0 regionalismo sul-americano}

Unasul's process of decline: causes and consequences for South American regionalism

\section{El proceso de declive de la Unasur: causas y consecuencias para el regionalismo sudamericano}

Diego Antunes'

D0I: 10.5752/P.2317-773X.2021v9.n1.p131

Recebido em: 03 de abril de 2020

Aceito em: 02 de agosto de 2020
1. Mestre e Doutorando em Ciência Política pela Universidade Federal do Rio Grande do Sul, Porto Alegre, Brasil. ORCID ID: https://orcid.org/0000-00028203-2756.

\begin{abstract}
RESUMO
Celebrada em seus anos iniciais como marco do regionalismo sul-americano, a União de Nações Sul-Americanas (Unasul) é hoje caracterizada por um esvaziamento funcional e abandono pela maior parte dos países do subcontinente. Dada a magnitude da organização e os ambiciosos objetivos a ela atribuídos, o processo de declínio e atual ostracismo da Unasul levanta a questão acerca de qual o significado da queda da organização para a América do Sul. A fim de trabalhar tal problemática, o presente artigo se vale de revisão de documentos primários e secundários a fim de detalhar o processo de declínio da Unasul, abordando suas causas e suas implicações, enquadrando-a enquanto instrumento de organização da América do Sul em um polo de poder perante o sistema internacional multipolar do século XXI. Conclui-se que a América do Sul não pode se abster de um instrumento institucionalizado de cooperação e organização regional, mas que novas empreitadas regionalistas devem evitar erros cometidos na construção da Unasul. Em especial, é necessário repensar o caráter intergovernamental do regionalismo sul-americano e a consequente ausência de autonomia por parte das organizações criadas.
\end{abstract}

Palavras chave: Unasul. Organizações internacionais. Regionalismo sul-americano.

\footnotetext{
AbSTRACT

Celebrated in its early years as a milestone in South-American regionalism, the Union of South American Nations (Usan) is nowadays characterized by functional emptiness and abandonment by the majority of the countries in the region. Given the organization's magnitude and ambitious goals, its decline process and current ostracism raises the question on what is the meaning of such process for South America. In order to examine this question, this article makes use of pri-
}

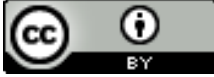


mary and secondary bibliography review aiming to specify the decline process of the Unasul as well as its causes and implications, ascribing it as instrument of regional organization towards making South America a regional power into the twenty-first century multipolar international system. The article concludes that South America cannot abstain itself of a institutionalized instrument of regional cooperation and organization, but new regionalist endeavors must avoid mistakes made with Unasul. In particular, it is necessary to rethink the intergovernmentalist approach of South American regionalism as well as the lack of autonomy by regional organizations.

Keywords: Usan. International organizations. South American regionalism.

\section{RESUMEN}

Celebrada en sus primeros años como un hito del regionalismo sudamericano, la Unión de Naciones Suramericanas (Unasur) se caracteriza hoy por un vaciamiento funcional y un abandono por parte de la mayoría de los países del subcontinente. Dada la magnitud de la organización y los ambiciosos objetivos que se le atribuyen, el proceso de decadencia y el ostracismo actual de Unasur plantea la pregunta sobre qué significó la caída de la organización para América del Sur. Para abordar este tema, este artículo utiliza una revisión de documentos primarios y secundarios para detallar el proceso de declive de Unasur, abordando sus causas e implicaciones, encuadrándola como un instrumento de organización de América del Sur en un polo de poder frente al sistema internacional multipolar del siglo XXI. Se concluye que la América del Sur no puede abstenerse de un instrumento institucionalizado de cooperación y organización regional, pero que nuevas iniciativas regionalistas deben evitar los errores cometidos en la construcción de Unasur. En particular, es necesario repensar el carácter intergubernamental del regionalismo sudamericano y la consiguiente falta de autonomía por parte de las organizaciones creadas.

Palabras clave: Unasur. Organizaciones internacionales. Regionalismo sudamericano.

Introdução

Detentores de um passado colonial europeu comum e inseridos numa região relativamente pacífica em termos de guerras, os países sul-americanos historicamente registram uma dinâmica cíclica de processos de aproximação e distanciamento entre si. Costumeiramente, os momentos de aproximação são explicados em termos de regionalismos, os quais são temporalmente localizados: o regionalismo fechado dos anos sessenta a oitenta (constituição de mercado regional para a substituição de importações), o regionalismo aberto dos anos noventa (constituição de blocos comerciais para a liberalização e integração dos mercados regionais ao comércio mundial) e o regionalismo pós-liberal dos anos 2000 (agenda política e integração pela autonomia dos mercados e governos regionais perante as grandes potências) (SENHORAS, 2010, p. 2; FIGUEIREDO, 2014, p. 139).

Trata-se de um processo iniciado com a ALALC já em 1960 - algo que faz da integração latino-americana um fenômeno tão antigo quanto o processo europeu - e que culmina no afunilamento da integração na América do Sul com a criação da Unasul em 2008, expressão importante do regionalismo pós-liberal. Com um tratado constitutivo de objetivos 
abrangentes que iam desde o desenvolvimento e superação das assimetrias entre os Estados até a afirmação de políticas sociais e proteção de minorias, passando por questões de infraestrutura continental, promoção da democracia e meio ambiente (UNASUL, 2008), a Unasul dividiu analistas e observadores em pessimistas e otimistas quanto às possibilidades da organização alcançar suas metas e promover a integração regional sul-americana.

Nesse sentido, enquanto Ventura e Baraldi (2008, p. 14) se perguntavam se a Unasul não seria mero "fogo de artifício retórico", Moraes (2015, p. 77) afirmava que "a próxima etapa do state-building brasileiro se confundirá com a construção de um espaço público regional integrado. O eixo desse processo de construção regional será a Unasul”. Também para Rafael Araujo (2011, p. 26), a Unasul conferiria "irreversibilidade" do processo de crescimento da influência e do protagonismo da América do Sul no mundo.

O teste do tempo, contudo, parece ter favorecido as visões mais pessimistas. Onze anos após o lançamento de sua Carta Constitutiva, a Unasul se encontra hoje esvaziada. Desde 2014 a organização não realiza a Cúpula das Chefas e Chefes de Estado e de Governo, única instância com poder real de decisão cuja ocorrência deveria ser anual. Também desde 2014 a Unasul falha em eleger um Secretário Geral, dado que os países não conseguem chegar ao consenso acerca de um nome para ocupar o cargo. Adicionalmente, a sede da organização foi fechada no início de julho de 2018 e, no fim do mesmo mês, a Colômbia anunciou sua saída, a qual se deu sem qualquer entrave. Desde então, Argentina, Brasil, Chile, Equador, Paraguai e Peru denunciaram o tratado constitutivo.

Dada a vasta abrangência geográfica e funcional conferidas à Unasul, torna-se razoável considerar que seu enfraquecimento e estagnação implicam em consequências importantes para o regionalismo sul-americano e para a América do Sul como um todo. Dessa forma, o problema que move a presente pesquisa pode ser sintetizado na seguinte pergunta: qual o significado do fim da Unasul para o subcontinente sul-americano? Como objetivo norteador da pesquisa, busca-se compreender o papel da organização para a região sul-americana, bem como o processo pelo qual esta perdeu força ao longo dos anos.

A importância dessa investigação reside na necessidade de projetar os rumos da região no atual momento de redefinição da política internacional regional e mundial. Seria, como colocam Carvalho e Bressan (2017, p. 104), a Unasul um mero hiato entre a histórica dominação latino-americana pelos Estados Unidos e a ascendente influência chinesa na região? Está o regionalismo pós-hegemônico fadado a desaparecer junto com a organização que lhe deu maior expressão? É razoável antever o retorno de uma América do Sul pautada primordialmente por um regionalismo estritamente comercial, focado no Mercosul, na CAN e na Aliança do Pacífico? Aprofundar o entendimento sul-americano sobre os rumos de seu atual regionalismo é uma tarefa de suma importância na elucidação desses questionamentos.

Assim, este trabalho se organiza da seguinte forma: além desta introdução, a segunda seção busca entender como a Unasul foi afirmada 
enquanto instrumento de constituição da América do Sul em um polo de poder regional; a terceira seção analisa seu processo de desgaste a partir de sua dimensão institucional e dos aspectos conjunturais que embasaram o modelo intergovernamental de integração; a quarta seção busca compreender as relações entre esse o modelo institucional e a política externa brasileira; por fim, a quinta seção apresenta as implicações da ausência de um foro sul-americano consolidado para o subcontinente através do conceito de bens públicos regionais.

\section{A América do Sul perante o mundo: integração regional e autonomia}

Enrijecidas desde o fim da Segunda Guerra Mundial numa bipolaridade global, as relações internacionais transformaram-se profundamente com o fim da Guerra Fria, passando para uma fase de ascensão de potências regionais, multilateralização dos acordos e afirmação de um sistema multipolar pautado por mecanismos globais e regionais de cooperação e integração em favor do desenvolvimento e da estabilidade política. Nessa nova era de globalização, cresceram as projeções acerca da crescente preeminência do internacional sobre o doméstico, com as forças globalizantes colocando em questão a integridade das soberanias nacionais, especialmente dos países menos desenvolvidos (CERVO, 2008).

A preocupação em capacitar a região sul-americana frente à globalização e às incertezas do mundo multipolar fez-se presente nos anos 2000, momento em que a ascensão de governos de esquerda e centro-esquerda na América Latina provocou uma transformação do regionalismo liberal até então vigente, voltado ao livre mercado. Com a Cúpula de Presidentes da América do Sul, em 2000, inicia-se um esforço diplomático regionalmente concertado que paulatinamente dá forma a projetos tais como a Iniciativa para a Integração da Infraestrutura Regional Sul-Americana (IIRSA), a Comunidade Sul-Americana de Nações (CASA) e a União de Nações Sul-Americanas (Unasul), em 2008. A criação desta última, por sua vez, deveu-se fortemente à liderança de países como Brasil, Venezuela e Argentina, mas a organização logrou integrar os doze Estados da América do Sul, com seu Tratado Constitutivo entrando em vigor em 2011 (GRASSI; CASA, 2019).

Nesse sentido, a Unasul é comumente afirmada como instrumento chave na constituição da região como um polo de poder. Nas palavras de Samuel Pinheiro Guimarães:

$$
\begin{aligned}
& \text { Para que o Brasil e a América do Sul [...] possam ser capazes de defender } \\
& \text { efetivamente seus interesses de longo prazo em um mundo instável, violento e } \\
& \text { arbitrário, é indispensável trabalhar de forma consistente em favor da emergência } \\
& \text { de um sistema mundial multipolar no qual a América do Sul venha a constituir } \\
& \text { um dos polos e não ser apenas uma sub-região de qualquer outro polo econômi- } \\
& \text { co ou político (GUIMARÃES, 2006, p. 275). }
\end{aligned}
$$

No mesmo sentido, Senhoras (2010) argumenta que a "regionalização transnacional da América do Sul”, catalisada pela Unasul, estaria associada não apenas à busca do desenvolvimento regional, mas também à construção de resistência aos efeitos de uma globalização assimétrica. Para Barnabé, esse processo se daria através do potencial de organizações 
como a Unasul de limitar a diminuição de autonomia dos Estados ao lhes conferir "novo papel no cenário regional/global e recuperando sua capacidade de regulação interna” (BARNABÉ, 2011, p. 47).

Uma forma objetiva pela qual a Unasul se colocou como sustentáculo de um projeto de fortalecimento regional seria pela substituição de um mecanismo de governança hemisférica - a Organização dos Estados Americanos (OEA) - onde a preponderância estadunidense seria determinante, pelo mecanismo subcontinental da Unasul, no qual a autonomia de lideranças regionais seria maior (OLIVEIRA, 2017). Tal processo seria importante pela anulação de laços de dependência pactuados em mecanismos de regulação extra regionais (BRAYNER, 2016).

Essa substituição da OEA pela Unasul é verificável nas crises regionais que a segunda intermediou, tais como as instabilidades separatistas que abalaram a Bolívia em 2008. Na ocasião, a oposição de setores conservadores da sociedade boliviana à reforma constitucional proposta pelo presidente Evo Morales instaurou uma onda de violência, a qual culminou no "Massacre de Pando", episódio que deixou inúmeros mortos e desaparecidos. Acusado de conspirar com as forças opositoras pela derrubada do governo, o embaixador estadunidense em La Paz foi expulso do país, afastando os EUA da resolução do conflito.

A intermediação da Unasul se deu com base na instituição de documentos oficiais como a Declaração de Moneda, pela qual a organização se colocava como mediadora entre os opositores e o governo. O resultado foi a contenção do espraiamento das hostilidades e o apaziguamento das relações internas bolivianas, registrando o primeiro caso de uma grave instabilidade regional sul-americana resolvida sem a participação dos Estados Unidos (SERBIN, 2009; LYRA, 2017).

Processo semelhante se deu no Equador em 2010. A tentativa do presidente Rafael Correa de instaurar uma nova constituição que estabeleceria profundas mudanças no sistema econômico equatoriano inspirou profunda oposição de diversos setores da sociedade, inclusive da polícia nacional, que declarou greve e tomou o Aeroporto de Quito e a Assembleia Nacional. Em resposta, a Unasul instituiu declaração em repúdio ao que fora identificado como uma tentativa de golpe e, mais tarde no mesmo ano, instaurou a "Cláusula Democrática" (ou Protocolo sobre o Compromisso Democrático) de proteção à estabilidade dos regimes democráticos na região.

Trazer a resolução das crises regionais para o âmbito da região em si, sem a interferência de atores externos, é apontado como uma das conquistas da Unasul e um interesse consensual comum entre os países sul-americanos que poderia embasar o processo integracionista como um todo (BARNABÉ, 2011). Assim, é sintomático que a fase de estagnação da organização, iniciada em $2014^{2}$, seja precedida pela crise paraguaia de 2012, desatada pela deposição do presidente Fernando Lugo. O episódio registrou fortes críticas à atuação vacilante do Brasil, último país sul-americano a se posicionar com relação ao governo de Frederico Franco (BASTOS; METZGER, 2012). O envio de uma missão da Unasul ao país para ouvir a defesa de Lugo e professar a necessidade de cumprimento da Cláusula Democrática não surtiu efeitos práticos ou qualquer alteração
2. Argumenta-se pelo ano de 2014 como início da estagnação da Unasul por ser o momento em que o Conselho de Chefas e Chefes de Estado e de Governo (CCCEG), órgão máximo da organização, deixa de ter reuniões anuais tal como estipulado pela Carta Constitutiva - em razão do fim do consenso que sustentou o processo decisório da Unasul nos anos anteriores. As atividades da organização vão paulatinamente sendo deslocadas para o conselho de Ministras e Ministros de Relações Exteriores, que, no entanto, é um órgão subordinado ao CCCEG. 
3. Informações disponíveis em: http:// www. itamaraty.gov.br/pt-BR/politica-externa/integracao-regional/13221-documentos-da-uniao-de-nacoes-sul-americanas. Acesso em 31 mar. 2020

4. Mais informações sobre a crise venezuelana podem ser encontradas em Vaz (2017).

5. Os grupos ad hoc são o Grupo de Montevideo, defensor de uma transição negociada e gradual; e o Grupo do Rio, que junto com a OEA, advoga por uma saída imediata do presidente Maduro e por novas eleições. Nesse processo, a OEA passa a ser o fórum regional primordial de tratamento à crise (ESTADO

DE MINAS, 2019), em detrimento da Unasul.

6. Na ocasião, Venezuela, Bolívia, Suriname e Equador não aceitaram a candidatura de José Octávio Bordon à secretaria-geral, contrariando Argentina, Brasil, Chile, Colômbia, Paraguai e Peru.

7. A última reunião da Cúpula ocorreu em Quito, no Equador, em 5 de dezembro de 2014 (ITAMARATY, 2014). na situação. Pondo-se em via contrária à organização sul-americana, a OEA instituiu uma nota reconhecendo o novo governo e a legalidade do processo de impeachment (SANTOS, 2018).

No mesmo sentido tem-se a crise venezuelana, observada pelo menos desde 2013 com a queda dos preços do petróleo, o desgaste das relações intergovernamentais e o levante de setores opositores contra o governo de Nicolás Maduro. Entre 2012 e 2016, a Unasul publicou um total de 11 documentos - entre Declarações do Conselho de Chefas e Chefes de Estado e de Governo e do Conselho de Ministras e Ministros de Relações Exteriores - através dos quais foram instituídas três missões de acompanhamento eleitoral (eleições presidenciais de 2012 e 2013 e parlamentares de 2015), comunicados de rechaço às sanções americanas aprovadas em Decreto Executivo de 2015, além de vários comunicados instando a necessidade de preservação da ordem democrática e valorização do diálogo entre governantes e opositores ${ }^{3}$. Para todos os efeitos, contudo, as ações da Unasul não foram suficientes para auxiliar na estabilização da situação venezuelana, cuja crise persiste até os dias atuais ${ }^{4}$. Nesse sentido, a organização foi paulatinamente eclipsada pela OEA e por grupos internacionais ad hoc ${ }^{5}$ no gerenciamento da crise.

É diante da ausência de solução à crise venezuelana que os sinais de uma crescente cisão interna entre os países da América do Sul vão surgindo. A falta de consenso numa organização intergovernamental significou a impossibilidade dos países membro elegerem o novo secretário geral em 2014, dado que não se chegou a um consenso sobre o nome que deveria suceder o colombiano Andrés Pastrana ${ }^{6}$. Também indicativo da crescente crise na integração sul-americana é o fato de a Cúpula das Chefas e Chefes de Estado e Governo, única instância com capacidade real de decisão na Unasul, não ser realizada desde $2014^{7}$, sendo sua ocorrência anual, segundo estipulação da Carta Constitutiva.

Assim, seguindo a argumentação dos autores que colocam a Unasul como sustentáculo de um projeto de constituição da América do Sul num polo de poder, torna-se razoável considerar o enfraquecimento desse projeto junto com o enfraquecimento da Unasul em si. Como a Unasul se ligaria à ideia de um polo de poder? De acordo com Gelson Fonseca Jr. (1998, p. 7), tais polos traduziriam a ideia de centragens de recursos de poder internacional em diferentes regiões do mundo, num processo possibilitado pelo fim da Guerra Fria que se identifica com a multipolarização do sistema internacional. É do interesse dos Estados assegurarem uma distribuição equilibrada de poder a fim de garantir condições políticas e estratégicas de autonomia soberana.

Mas de que forma trabalhar essa ideia quando sua aplicação é buscada por meio de um projeto regionalista? Seria esse polo de poder o fortalecimento da região frente o mundo, ou o fortalecimento dos países que compõem tal região? Ainda que a indagação pareça mera questão semântica, suas implicações são importantes: um processo de integração voltado ao fortalecimento da região poderia se dar nos moldes de um direito comunitário, de mecanismos de resolução de controvérsias e de uma organização supranacional de decisões vinculatórias - o que redundaria, teoricamente, na relativização da capacidade soberana dos Estados 
envolvidos (TILLMAN, 2015). Por outro lado, um processo de integração voltado ao fortalecimento dos países se pautaria, mais logicamente, pela construção de uma organização intergovernamental pela qual os Estados detêm controle sobre o processo, sob o objetivo de uma melhor inserção estratégica dos países da região.

Historicamente, a América Latina se caracterizaria por priorizar a segunda opção, mantendo um padrão de integração regional intergovernamental, soberanista e consensualista (PINCHEMEL, 2016) que, no entanto, tem como consequência a manutenção de organizações integracionistas demasiadamente dependentes dos Estados nacionais e de conjunturais disposições dos mesmos aos avanços da integração. Assim, de acordo com Fucille, Ramanzini Junior e Almeida (2017, p. 49), a Unasul teria inovado ao assumir o papel de fortalecedora da autonomia soberana dos Estados ao proteger a região de interferências externas, dado que, no geral, processos de integração regional redundam na relativização da margem de manobra dos Estados envolvidos.

A caracterização da Unasul enquanto "modelo soberanista" de integração regional é afirmada já no tratado constitutivo quando, no preâmbulo, consta que os países signatários ratificam "que tanto a integração quanto a união sul-americanas fundam-se nos princípios basilares de: irrestrito respeito à soberania, integridade e inviolabilidade territorial dos Estados" (UNASUL, 2008, p. 1). Importa inquirir, nesse sentido, quais as implicações desse modelo soberanista de integração ao regionalismo sul-americano e como ele se relaciona com o processo de defasagem da integração sul-americana.

As implicações do modelo institucional intergovernamental à integração regional sul-americana

A integração regional pode ser entendida como um processo no qual as unidades políticas isoladas e autônomas são direcionadas à aproximação e ulterior unificação de domínios funcionais e políticos por meio da cooperação e do estabelecimento progressivo de novas formas de governança (LOMBAERDE; LANGENHOVE, 2006, p. 13; HERZ, HOFFMANN, 2004, p. 168). Dependendo do embasamento teórico com o qual se trabalha, diferentes aspectos podem ser adicionados à essa definição. Por exemplo, se a visão de integração partir de uma matriz neofuncionalista, considera-se que o fim último do processo integracionista é o alcamce da governança supranacional, ancorada na transferência de lealdades nacionais para com a organização comunitária (HAAS, 1958).

A supranacionalidade, por sua vez, faz referência a um tipo de jurisdição, investida em estruturas de integração regional, caracterizada por processos decisórios de maioria qualificada cuja aplicação é imediatamente reconhecida, sem necessidade de posterior aprovação estatal. Seria resultado de um processo de integração marcado pela concessão de soberania por parte dos governos nacionais envolvidos, que passariam a se sujeitar a um direito comunitário hierarquicamente superior à jurisdição nacional, dentro do âmbito estipulado pelos objetivos do processo de integração. Assim, a estrutura supranacional figuraria como meio termo en- 
tre organização internacional e federação (VERDROSS, 1980; GÓMEZ, 2012; TILLMAN, 2015; HAAS, 1958; SWEET; SANDHOLTZ, 1998).

Por extensão, a contraparte da supranacionalidade, a intergovernamentalidade, seria um regime institucional em que os Estados-membro detêm controle sobre a estrutura integracionista através da manutenção de sistemas decisórios baseados na unanimidade consensual das representações nacionais; e onde os termos dos tratados que embasam a integração e que constituem a organização são aplicados de forma controlada pelos Estados (FONSECA; 2010, TILLMAN, 2015).

Em geral, o alcance da supranacionalidade se revela como um objetivo de difícil alcance. No lugar de arranjos supranacionais que exerçam poder autônomo sobre os Estados, a maioria dos processos de integração regional "freia" no nível intergovernamental, no qual as decisões não são executadas pela organização integracionista, mas sim pelo voto consensual dos Estados que, por meio da barganha e de manobras diplomáticas, conseguem direcionar as decisões relativas de acordo com seus objetivos particulares, nacionais.

Nesse sentido, é possível afirmar que a integração intergovernamental coaduna com o objetivo de manutenção da soberania dos Estados, ao contrário da relativização das mesmas exigida por uma instituição efetivamente supranacional. É nesse sentido que se compreende a persistência com que os termos "consenso" e "soberania" figuram na Carta Constitutiva da Unasul, evidenciando a opção institucional feita pelos Estados-membro.

Durante a fase de criação da Unasul, houveram propostas de fazer dela uma organização supranacional. O ex-presidente equatoriano Rodrigo Borja Cellos defendia, em reunião da Comissão de Altos Funcionários em 2008, a inclusão de um artigo na Carta Constitutiva que tornasse a organização supranacional, argumentando que a Unasul não teria capacidade de perseguir seus objetivos com um recorte intergovernamental. A derrota de sua proposta fez o ex-presidente, então apontado como o primeiro Secretário-Geral, a renunciar do cargo em maio do mesmo ano. A proposta de institucionalizar uma Secretaria Geral forte, embrião de uma futura supranacionalidade, também foi derrotada diante da opção feita por um Secretário Geral aos moldes do Mercosul, o qual atua sob expresso mandato dos Estados (FIGUEIREDO, 2014, p. 143-144).

O que essas propostas viam era a possibilidade de viabilizar as decisões da Unasul como automaticamente vinculatórias aos ordenamentos jurídicos internos dos Estados membro, concentrando seu processo decisório na Unasul em si. Ao invés disso, de acordo com o caráter intergovernamental, o que se estipulou foi que os "atos normativos emanados dos órgãos da UNASUL serão obrigatórios para os Estados Membros uma vez que tenham sido incorporados no ordenamento jurídico de cada um deles, de acordo com seus respectivos procedimentos internos" (UNASUL, 2008, p. 10). Ou seja, as decisões tomadas no âmbito da Unasul precisavam ser individualmente internalizadas por cada um dos doze governos para que ela possa surtir efeito verdadeiramente regional.

A necessidade de os países da Unasul buscarem apoios domésticos posteriores às negociações internacionais para aprovação parlamentar e 
internalização das decisões não só foi um obstáculo a mais à efetividade da organização, como pode ser usado estrategicamente por países relutantes em aceitar a decisão no nível comunitário. De acordo com Figueiredo (2014, p. 148), isso seria benéfico no sentido de respeitar a assimetria entre os países envolvidos, mas enfraqueceria a capacidade da Unasul de alcançar seus objetivos. Exemplo claro dessa dinâmica seria o Protocolo Adicional ao Tratado Constitutivo sobre o Compromisso com a Democracia - também referido como "Cláusula Democrática" - o qual regulamentaria a disposição dos doze países da Unasul em agir conjuntamente contra casos de ameaça ao regime democrático. Apesar de assinado pelos doze países em 2010 (HOFFMANN, 2016, p. 53), o protocolo só seria internalizado pelo maior deles em 2017, quando o Congresso Nacional brasileiro ratifica o tratado (SENADO FEDERAL, 2017).

Somando-se isso ao fato de o regime decisório ser baseado no consenso - uma decisão só pode ser tomada por absoluta anuência de todos os doze Estados - tem-se uma ideia de porque a organização experimentou uma paralisia decisória desde 2014. Se de um lado países como Brasil, Argentina e Colômbia sustentaram uma posição de deslegitimação do atual governo de Nicolás Maduro, na Venezuela; por outro, países como Bolívia e, até recentemente, Equador, buscavam defender a não interferência nos assuntos internos do país. Tal embate foi transplantado ao âmbito da Unasul, quando o secretário geral a ser eleito em 2014 - ano em que o mandato do então secretário Andrés Pastrana expirava - não foi eleito. A estipulação de um nome que atendesse os interesses de algum dos lados na crise venezuelana não foi possível dada a regra do absoluto consenso.

Esse impasse acerca de quem comandaria os trabalhos da organização perante a crise venezuelana se tornou a raiz do esvaziamento da Unasul. Os seis países que suspenderam suas atividades - Argentina, Brasil, Chile, Colômbia, Paraguai e Peru - remeteram, em 19 abril de 2018, uma carta à presidência pro tempore da Unasul comunicando sua decisão e a justificando com base na recusa de Venezuela, Bolívia, Suriname e Equador em votar a favor do argentino José Octácvio Bordón à Secretaria-Geral (QUEIROZ, 2018). Ao longo da primeira metade de 2019, os mesmos seis países, acrescidos em março pelo Equador, foram um a um denunciando o tratado constitutivo do bloco, formalizando sua retirada da organização. Esses mesmos países - mais a Guiana - se uniriam em março de 2019 em Santiago, no Chile, para criar o Fórum para o Progresso e Desenvolvimento da América do Sul (PROSUL), iniciativa voltada à substituição da Unasul por um bloco de integração comercial aos moldes da Aliança do Pacífico (JORNAL DO COMÉRCIO, 2019).

Assim, do ponto de vista institucional, torna-se razoável considerar o caráter intergovernamental - e a consequente obrigatoriedade do consenso no processo decisório - como causas principais da vulnerabilidade da Unasul perante instabilidades internas e redefinições de políticas externas nacionais - cujos efeitos redundaram no enfraquecimento do processo integracionista. Tal processo pode ser ilustrado quando se coloca em perspectiva as mudanças governamentais ocorridas na América do Sul ao longo da presente década. 
8. Dados disponíveis em: http://www. itamaraty.gov.br/pt-BR/politica-externa/ integracao-regional/13221-documentos-da-uniao-de-nacoes-sul-americanas\#decisoes. Acesso em 25 mar. 2020.
A Unasul tem seu processo de criação atrelado ao contexto dos anos 2000 , onde uma constelação específica de líderes de esquerda e centro esquerda, críticos à agenda neoliberal e à influência estadunidense na região, convergiram seus interesses na construção de uma organização de integração regional autônoma. Assim, a vigência do mandato de presidentes tais como Luís Inácio Lula da Silva (Brasil, 2003-2010), Nestor/Cristina Kirschner (20032015) ou Hugo Chávez (Venezuela, 1999-2013) formaram uma base subcontinental de apoio à agenda da Unasul em seus anos formativos (PINTO, 2019).

Contudo, o desgaste dessa coalizão - queda do petismo no Brasil, ascensão do direitista Fernando Macri na Argentina, chegada de Ivan Duque à presidência da Colômbia com a retomada de uma política externa voltada aos EUA - marca a corrosão da conjuntura favorável à construção consensual de uma agenda regionalista autonomista na América do Sul. Mais do que a desestruturação das condições de consenso preexistentes, contudo: observa-se um desmonte da organização proveniente de uma retomada conservadora regional que busca recuperar a pauta neoliberal na agenda regionalista (JAEGER, 2019).

O resultado é um processo de declínio e esvaziamento funcional de uma organização que não foi equipada para funcionar autonomamente. O gráfico I ilustra esse declínio a partir do critério da emissão de documentos oficiais:

\section{Gráfico 1 - Documentos oficiais produzidos pela UNASUL (2008-2018)}

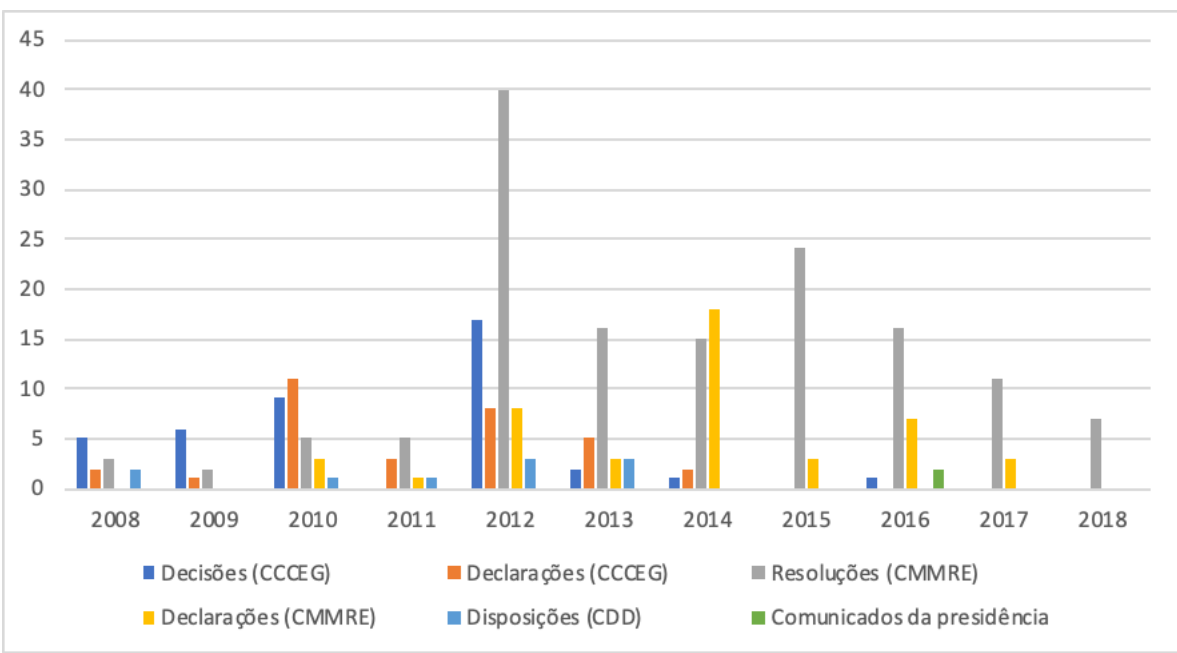

Fonte: Site do Itamaraty , elaboração própria.

O gráfico apresenta a quantidade absoluta de Declarações, Comunicados e Decisões emitidos pelo Conselho de Chefas e Chefes de Estado e de Governo (CCCEG), Declarações, Comunicados e Resoluções do Conselho de Ministras e Ministros de Relações Exteriores (CMMRE), Disposições do Conselho de Delegados e Delegadas (CDD) e Comunicados da Presidência Pro Tempore. Importante notar, contudo, que os únicos documentos com real aplicabilidade jurídica no âmbito da Unasul são as Decisões do Conselho (representadas, no gráfico, pelas barras azuis), as quais não ocorrem desde 2014 - com exceção de um parecer de 2016 prorrogando o mandato de Ernesto Samper como Secretário-Geral da organização 
até janeiro de 2017. Como se pode observar, o estancamento dos trabalhos do Conselho é acompanhado por uma tentativa do CMMRE de manter as atividades da Unasul, algo que foi declinando continuamente, chegando a apenas 7 Resoluções em 2018. Em 2019, esse número cai para 0, junto com todos os outros documentos oficiais, que deixam de ser emitidos.

Da mesma forma, o Orçamento Anual da organização, estipulado anualmente desde 2011, foi publicado pela última vez em 2017. Diferente da emissão de documentos oficiais, contudo, o orçamento anual registra uma trajetória de relativa estabilidade:

Gráfico 2 - Orçamento anual da UNASUL de 2011 a 2018 (em dólares americanos)

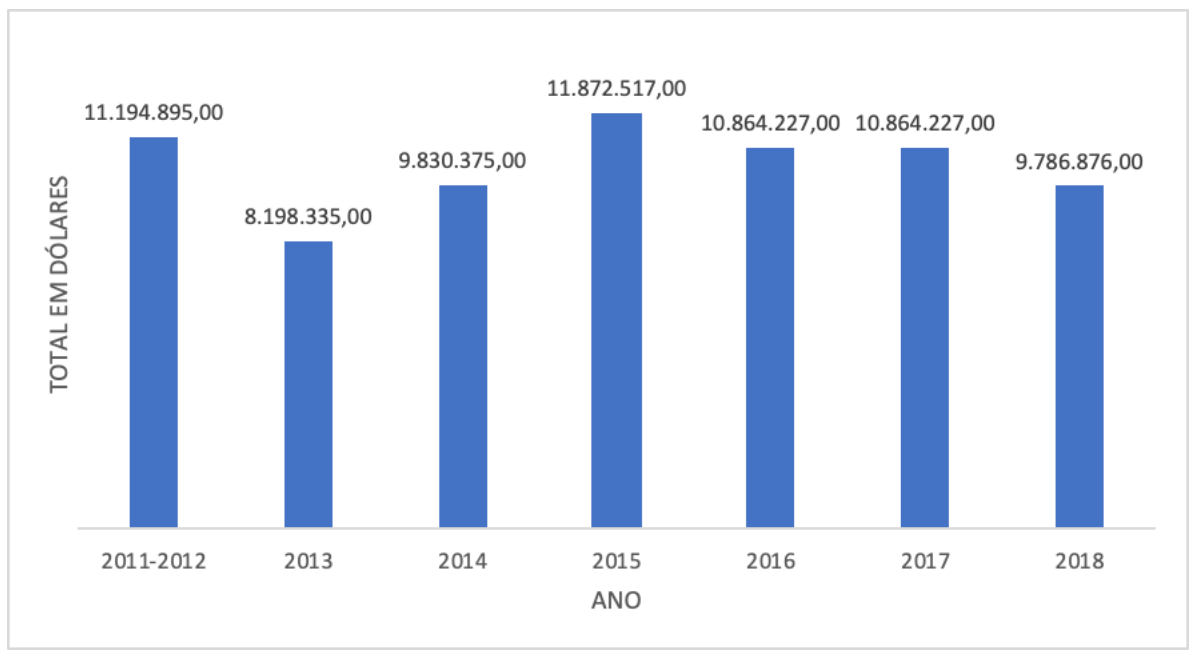

Fonte: Site do Itamaraty, elaboração própria.

Feita de maneira proporcional ao tamanho da economia de cada país, a composição do orçamento anual da Unasul confere diferentes cotas de contribução a cada Estado-membro. Como evidenciado na tabela I a seguir, a crise política desatada no interior da Unasul que culminou - ao longo de 2018 e 2019 - com a retirada e posterior denúncia do tratado por parte de Argentina, Brasil, Colômbia, Chile, Equador, Paraguai e Peru representou a perda de aproximadamente $83,8 \%$ do orçamento com o qual a organização operou ao longo de seus anos de funcionamento.

Tabela 1 - Média da cota de contribuição orçamentária de cada país-membro da unasul, entre 2013-2018* (\%)

\begin{tabular}{|l|l|}
\hline País & Média percentual \\
\hline Argentina & $16 \%$ \\
\hline Bolívia & $1 \%$ \\
\hline Brasil & $38 \%$ \\
\hline Chile & $7,1 \%$ \\
\hline Colômbia & $10 \%$ \\
\hline Equador & $3,7 \%$ \\
\hline
\end{tabular}

\begin{tabular}{|l|l|}
\hline País & Média percentual \\
\hline Guiana & $0,1 \%$ \\
\hline Paraguai & $1,2 \%$ \\
\hline Peru & $7,8 \%$ \\
\hline Suriname & $0,1 \%$ \\
\hline Uruguai & $1 \%$ \\
\hline Venezuela & $11 \%$ \\
\hline
\end{tabular}

Fonte: Site do Itamaraty, elaboração própria.

*0 orçamento de 2011-2012 não foi considerado no cálculo da média, por ter uma distribuição discrepante daquela consolidada nos anos posteriores. Sua exclusão do cálculo evita a criação de distorções. 
Os dados demonstram uma trajetória de declínio na dimensão política da organização, com consequências severas para a sustentabilidade financeira da organização. Tal declínio pode ser associado à estagnação do processo decisório político - esta que, por sua vez, deve-se às mudanças políticas ocorridas no subcontinente. Nesse sentido, dada a importância atribuída à Unasul em termos de constituição da América do Sul num polo de poder autônomo, por que os países sul-americanos optaram por uma integração intergovernamental consensualista, fortemente dependente de variáveis conjunturais ligadas à constelação de presidências em exercício ao longo dos anos 2000? Dado o peso de sua política externa e sua posição central para a formação da organização, o Brasil torna-se um objeto de análise essencial para compreender a opção pela intergovernamentalidade.

Política externa e interesses comunitários: o lugar da Unasul na política externa brasileira

De acordo com Matias Spektor (2014), a manutenção da autonomia é o objetivo último da política externa brasileira, pelo menos, desde os anos cinquenta, época em que o país teria adotado o "projeto autonomista”. Também segundo Amado Cervo (2008), a política externa brasileira caracteriza-se por basear-se em um "acumulado histórico" de oito princípios basilares à sua formulação. Dentre eles, a defesa da autodeterminação e da não-interferência são proeminentes princípios permanentes da postura diplomática nacional.

Essa preocupação da política externa brasileira com a autonomia do país frente o sistema internacional deriva, no entanto, de matrizes de pensamento teórico que perpassam a América Latina. As teorizações cepalinas dos anos cinquenta, por exemplo, já advogavam pelo rompimento de laços de dependência através do emprego da integração econômica em prol da substituição de importações e da industrialização dos países latino-americanos - tendo tais proposições embasado a criação da Associação Latino-Americana de Comércio (ALALC). Não à toa, muitos dos autores cepalinos passaram ao longo dos anos a trabalhar com a chamada "Teoria da Dependência” (BIELSCHOWSKY, 2018).

Em uma perspectiva mais política, também a "Escola da Autonomia" de Hélio Jaguaribe e Juan Carlos Puig formou, ao longo dos anos setenta e oitenta, uma concepção de mundo na qual o sistema internacional não seria anárquico, mas sim hierárquico, com diferentes países desfrutando de diferentes níveis de autonomia. A conquista de margens de manobra por parte dos países latino-americanos seria, nessa visão, condicionada pelas capacidades estruturais do país (congregadas no conceito de "viabilidade nacional"), as quais deveriam ser aprimoradas por processos de integração regional baseados na solidariedade e dotados de mecanismos que garantissem a inserção autônoma da América Latina no sistema internacional (RUIZ; LOMBAERDE, 2018).

A conjugação da integração regional com objetivos de autonomia política, portanto, tem longa tradição teórica na América Latina. Nesse sentido, a posição autonomista brasileira seria coerente com um processo 
de integração regional parcial, limitado à cooperação intergovernamental e distante de arranjos supranacionais. Observada à luz desses objetivos, portanto, a análise da política externa do Brasil durante os anos de criação da Unasul oferece elementos que permitem encaixar a integração regional limitada dentro do quadro de interesses brasileiros autonomistas e relativos ao estabelecimento de sua a liderança regional.

Assim, a política externa dos governos Lula (2003-2010) caracterizou-se por uma premissa, presente na formulação da mesma, acerca da ideia do Brasil como potência emergente no Sistema Internacional do século XXI. Essa premissa, combinada com a percepção de uma ordem internacional multipolar substituindo a unipolaridade dos anos noventa, teria levado o país a agir de acordo com os conformes de potência média em âmbito global. Assim, no âmbito continental, o desdobramento lógico dessas premissas se traduziu no constate esforço brasileiro de se afirmar como liderança regional sul americana (DIAS, 2014; PECEQUILLO, 2008).

Dentro da constelação de objetivos e posturas de política externa e, em consonância com os propósitos supramencionados, uma das grandes linhas reivindicativas da diplomacia brasileira na primeira década do século XXI disse respeito à reforma dos arranjos institucionais multilaterais globais. Desde as cobranças por maior representatividade democrática no Conselho de Segurança da ONU até a defesa de maior atuação da OMC contra o protecionismo comercial internacional, houve uma preocupação constante com a maior representatividade e eficiência dessas estâncias. Nesse sentido, iniciativas como o BRICS, IBAS, G-22 e Unasul, apesar de contarem com seus respectivos contextos e objetivos específicos, têm, segundo Pecequillo (2008), o denominador comum de fornecerem uma ferramenta de barganha e congregação de votos aliados no âmbito dos foros multilaterais.

Uma preocupação constante da política externa de Lula foi angariar prestígio internacional ou, colocado de outra forma, maior legitimidade e aceitação subjetiva para com as ações e aspirações do país no exterior. Nesse sentido, Pecequillo (2008) argumenta que a atuação do Brasil sobre a crise venezuelana de 2008 ou a liderança das Forças Armadas brasileiras dentro da missão de paz da ONU no Haiti figuraram, dentre outras coisas, como tentativa do país de vender a imagem de "potência estabilizadora" dentro do subcontinente sul-americano e da América Latina. Como já demonstrado, a Unasul serviu de importante instrumento de mediação e contenção de crises e controvérsias regionais.

Nesse mesmo sentido, a ideia de uma liderança regional brasileira atuando dentro da América do Sul converge com o esforço do país em enfraquecer a influência estadunidense na região. Dessa forma, ainda que os norte-americanos tivessem presença inquestionável na Colômbia, o Brasil poderia argumentar pela ausência de necessidade de atuação dos EUA em outras situações de crise e potencial insegurança na região, tais como a instabilidade boliviana de 2008. Sob essa ótica, a campanha brasileira pela criação de um conselho de defesa capaz de regionalizar a agenda de segurança e estabelecer a América do Sul como zona de paz ganha contornos mais claros. 
Conformar a integração regional com os auspícios de liderança regional e autonomia internacional explica os ânimos brasileiros de dar forma à Unasul sem, no entanto, trabalhar por uma integração que fosse além da intergovernabilidade e estabelecesse uma burocracia supranacional. Manter o órgão nesse nível moderado de cooperação convergiria com Vizentini (2006, p. 65) quando este afirma que o ex-presidente Lula, mandatário brasileiro durante os anos de criação da Unasul, preferiu inserir o Brasil em coalizões menos rígidas tais como BRICS ou IBAS que lhe permitissem manobrar com mais eficiência suas ações sem, contudo, amarrar a política externa brasileira a blocos rígidos. A resistência na criação de um órgão sul-americano supranacional pode ser lida dentro dessas linhas.

Evidencia-se, dessa forma, a tensão constante entre integração regional e autonomia nacional, dada as lógicas conflitantes que embasam as duas concepções: de um lado, a afirmação e o fortalecimento de aspectos individuais e próprios do Estado nacional; de outro, a intensificação de fluxos de interdependência coordenada e a consequente relativização da soberania estatal. Seria razoável considerar que um Estado confrontado com tal dilema deveria atribuir prioridade para um dos dois lados da moeda e, consequentemente, enfraquecer a alternativa. A manutenção da Unasul como um projeto de integração regional intergovernamental, incompleto e, em última análise, enfraquecido, acabou por deixar a integração regional sul-americana vulnerável a distorções e esvaziamentos que atrasaram e estancaram sua evolução.

Implicações do abandono da Unasul para a América do Sul

A Unasul se apresentava e foi apontada como base para defesa da autonomia regional da América do Sul frente a conjuntura internacional do novo milênio. Quais, portanto, são as consequências do desmantelamento dessa organização para a América do Sul? De acordo com o que foi exposto anteriormente, a principal e mais imediata consequência é a ausência de um órgão decisório subcontinental capaz de arquitetar a agenda regional e afirmar a autonomia sul-americana. Para tal, o contexto da América do Sul atual é ilustrativo.

Com relação à crise venezuelana, por exemplo, é notável que a Unasul passou a ser eclipsada pela atuação da OEA, que recuperou sua preeminência regional, bem como de grupos ad hoc voltados a defender o regime venezuelano ou sua transição. De um lado, tem-se o Grupo de Lima (Brasil, Canadá, Chile, Colômbia, Costa Rica, Guatemala, Honduras, Panamá e Peru (ITAMARATY, 2020), cuja agenda gira em torno da deposição de Maduro e apoio à presidência de Juan Guaidó, líder da oposição. De outro lado, tem-se o Grupo de Montevideo (Uruguai, México, Bolívia, Costa Rica, Equador, Alemanha, Espanha, França, Holanda, Itália, Portugal, Reino unido e Suécia) o qual busca uma posição mais moderada de diálogo e convocação de novas eleições (TERRA, 2019).

Sobre a OEA, é válido ressaltar o jogo de forças que ocorre dentro da organização. Ao longo dos primeiros meses de 2020, três candidaturas para a Secretaria Geral da organização foram protocoladas, duas de- 
las (o peruano Hugo de Zela e a equatoriana María Espinosa) basearam suas campanhas na crítica à gestão do candidato à reeleição, o uruguaio Luis Almagro, acusado de fechar os trabalhos da OEA na perseguição aos regimes venezuelano, cubano e nicaraguense e de ser alinhado à política externa estadunidense para a América Latina. Apoiado pelos Estados Unidos, Brasil e outros oito países, Almagro se reelegeu em 20 de março de 2020 ao cargo (FRANCE PRESS, 2020). Sua reeleição pode ser interpretada como manutenção da OEA à frente da crise venezuelana, estendendo a influência estadunidense à América do Sul.

Importante salientar, nesse sentido, que a questão venezuelana transita por circuitos extra regionais de diálogo, situação que a Unasul buscava evitar ou, ao menos, gerenciar. Tanto a composição dos grupos de Lima e Montevideo quanto o retorno da OEA e da influência estadunidense permitem considerar que a solução da crise venezuelana, hoje, passa por atores e interesses que transcendem a América do Sul. O projeto de um subcontinente sul-americano autônomo em suas relações regionais, ligado à constituição da região num polo de poder, ficou de lado junto com a Unasul, organização que buscava lhe dar corpo. A própria existência de grupos ad hoc demonstra a ausência de um fórum decisório que propicie esse concerto regional de forma institucionalizada.

Outro exemplo é a Amazônia. Cobrindo uma área superior a 5.500.500 quilômetros quadrados e se estendendo pelos territórios de sete países sul-americanos (Bolívia, Brasil, Colômbia, Equador, Guiana, Peru, Suriname, mais a Guiana Francesa), a floresta amazônica é uma região que, quando afetada em sua inteireza, automaticamente apresenta desafios regionais ao norte do subcontinente. Ainda assim, nenhum concerto regional significativo foi registrado entre os países da região no tocante à contenção das chamas que assolaram o bioma amazônico no segundo semestre de 2019. A ausência de tal esforço deixou os países amazônicos mais vulneráveis à pressão internacional pela preservação da Amazônia, e os custos políticos dessa desorganização foram significativos (VASCONCELOS, CHIARETTI, 2020).

A questão amazônica é evidência dos desafios do atual mundo globalizado. A perenidade dos fenômenos regionais e internacionais impele aos Estados Nacionais a necessidade de atentarem ao provimento dos chamados "bens públicos regionais", sob a ideia de que em uma região existem agendas naturalmente partilhadas tais como a segurança, meio ambiente ou saúde pública (CASAS, 2015, p. 23-24). A atual conjuntura de pandemia em razão do alastramento global do COVID-19 exacerba a necessidade de concerto regional para o enfrentamento multilateral de um tipo de crise que não se pauta por fronteiras ou jurisdições nacionais.

Relações bilaterais, organizações ad hoc e blocos sub-regionais como o Mercosul ou a Comunidade Andina são ferramentas importantes, mas jamais terão a prontidão e previsibilidade de uma organização subcontinental capaz de integrar processos decisórios ou, ao menos, delegações nacionais num fórum de diálogo permanente. Da mesma forma, o fortalecimento da autonomia regional não pode sobreviver diante de crises que extravasam para interesses e atores extra regionais que não necessariamente se pautam por interesses da região. Numa era em que um 
vírus que desponta no longínquo interior chinês coloca todo o globo em quarentena, é imprescindível dotar a América do Sul de um foro político de concerto regional.

Considerações Finais

À Unasul, duas funções primordiais foram atribuídas, ambas partindo do mesmo princípio, mas tendo em vistas objetivos diferentes. De um lado, atribuiu-se à organização a responsabilidade de organizar as relações regionais sul-americanas de modo a resguardar a democracia, conter crises intranacionais e afirmar a soberania dos países da região através da afirmação da América do Sul como um polo de poder regional autônomo. De outro, a Unasul foi tida como ferramenta de inserção internacional autônoma e de projeção internacional de poder pelo Brasil. $\mathrm{Na}$ primeira acepção, o interesse era regional; na segunda, nacional. Ainda que convergentes contingencialmente, tais lógicas tornaram-se contraditórias no médio prazo.

Ao circunscrever a Unasul dentro de um projeto maior de projeção internacional em que as prioridades eram mais nacionais do que propriamente regionais, o Brasil atuou para fazer da Unasul uma organização bastante dependente do papel brasileiro de liderança regional enquanto força motriz de uma organização sem autonomia própria para atuar. As consequências desse forte atrelamento da Unasul à política externa brasileira foram, portanto, o enfraquecimento da integração como consequência do enfraquecimento da posição brasileira na política internacional, dada a conjuntura de crise doméstica que assolou o país a partir de 2014.

É importante salientar que a função da Unasul enquanto garantidora da soberania dos países sul-americanos e sustentáculo da autonomia da região frente o mundo não perdeu valor. Como evidenciado na última seção, o mundo é hoje menos multilateral do que na primeira década do presente século, mas isso não necessariamente significa que o Sistema Internacional tenha retrocedido a uma unipolaridade. A combinação da unilateralidade dos grandes poderes com a multipolaridade do sistema mantém margens de manobra para regionalismos e processos integracionistas ainda mais necessários numa ordem onde o respeito à soberania dos menores nem sempre é respeitada. Da mesma forma, a globalização e a relativização do instituto da soberania nacional enquanto tendências atuais impele os Estados nacionais à busca de instrumentos de conservação de autonomia. Nesse sentido, iniciativas como a Unasul são cruciais, mas elas devem ser montadas de forma a se sustentarem sobre as próprias pernas, sem a dependência para com um ou outro Estado de interesses mais nacionais do que propriamente regionais.

Referências

ARAUJO, Rafael. A presença do Brasil na América do Sul: integração regional e política externa brasileira em debate. XXVI Simpósio Nacional de História. São Paulo, 2011. 28 p. Disponível em: http://www.snh2011.anpuh.org/resources/anais/14/1299684839_ARQUIVO_ ApresencadoBrasilnaAmericadoSul-integracaoregionalepoliticaexternabrasileiraemdebate-ANPUHSP.pdf. Acesso em: 29 out. 2019. 
BARNABÉ, Israel Roberto. Unasul: desafios e importância política. Mural Internacional, Rio de Janeiro, [s.l.], a. 2, n. 1, p. 40-48, jun. 2011.

BASTOS, Fabrício Henricco Chagas; METZGER, Fabio. O caso Lugo ou qual Maquiavel o Brasil pretende ser? Conjuntura Austral, Porto Alegre, v. 3, n. 13, p.34-44, jul. 2012.

BIELSCHOWSKY, Ricardo. A Trajetória Histórica do Pensamento da Cepal: 1948-1998. In: BRANDÃO, Carlos Antônio (Org.). Teorias e Políticas do Desenvolvimento Latino-Americano. Rio de Janeiro: Contraponto, 2018, p. 47-92.

BRAYNER, André Vitorino Alencar. Direito À Integração Democrática Na América Do Sul: considerações políticas e jurídicas sobre a Unasul. 166 p. Dissertação (Mestrado em Direito Constitucional) - Universidade de Fortaleza, Fortaleza, 2016.

RUIZ, José Briceño; LOMBAERDE, Philippe de. Regionalismo latino-americano: produção de saber e criação e importação de teoria. Civitas - Revista de Ciências Sociais, [s.l.], v. 18, n. 2, p. 262, 7 ago. 2018.

CARVALHO, Daniel Campos de; BRESSAN, Regiane Nitsch. Unasul e a projeção brasileira. Perspectivas, São Paulo, v. 50, n. 1, p.87-110, jul./dez. 2017.

CASAS, Taiane Las. A integração regional como mecanismo para provisão de bens públicos: uma análise comparativa da agenda de segurança pública no Mercosul e na Comunidade Andina de Nações. Revista Brasileira de Política Internacional, [s.l.], v. 58, n. 1, p.23-41, jun. 2015.

CERVO, Amado. O final do século XX e início do século XXI: dificuldades para construção de uma ordem global. In: SARAIVA, José Flávio Sombra (Org.). História das relações internacionais contemporâneas: da sociedade internacional do século XIX à era da globalização. 2. ed. São Paulo: Saraiva, 2008. Cap. 9. p. 346-371.

DIAS, Luis Henrique Reis. Responsabilidade, segurança e identidade: a política externa brasileira nos governos Lula e Dilma. In: XXII Seminário de Iniciação Científica da PUCRio, Rio de Janeiro, 2014. Disponível em: http://www.pucrio.br/pibic/relatorio_resumo2014/relatorios_pdf/ccs/IRI/IRI-

Luis\%20Henrique\%20Reis\%20Dias\%20e\%20Marcelle\%20Trotte.pdf. Acesso em 24 ago. 2015.

ESTADO DE MINAS. OEA dividida sobre crise na Venezuela. Estado de Minas, Belo Horizonte, 2019. Disponível em: https://www.em.com.br/app/noticia/internacional/2019/01/24/ interna_internacional,1024306/oea-dividida-sobre-crise-na-venezuela.shtml. Acesso em: 11 jun. 2020.

GUIMARÃES, Samuel Pinheiro. Desafios brasileiros na era dos gigantes. Rio de Janeiro: Contraponto, 2006.

FIGUEIREDO, Alexandre Ganan de Brites. A União de Nações Sul-americanas: institucionalidade e desafios. Cadernos Prolam/usp, São Paulo, v. 24, n. 13, p.137-152, 2014.

FONSECA JUNIOR, Gelson. Anotações sobre as condições do Sistema Internacional no limiar do século XXI: a distribuição dos polos de poder e a inserção internacional do Brasil. Instituto de Estudos Avançados da USP, 1998. Disponível em: http://www.iea.usp.br/publicacoes/ textos/fonsecajrsistemainternacional.pdf. Acesso em 29 out. 2019.

FONSECA, Víctor. Avances y reformas pendientes en la institucionalidad de la integración centroamericana. In: BCIE. Cinco Ensayos sobre la integración de Centroamérica: los ganadores del concurso promovido por el BCIE con motivo de su 50 aniversario. BCIE, Tegucigalpa, 2010, p. 60-94.

FRANCE PRESS. Luis Almagro é reeleito secretário-geral da OEA. G1 Mundo, [s.l.], 20 mar. 2020. Disponível em: https://g1.globo.com/mundo/noticia/2020/03/20/luis-almagro-e-reeleito-secretario-geral-da-oea.ghtml. Acesso em 03 mar. 2020.

FUCILLE, Alexandre; RAMANZINI JUNIOR, Haroldo; DE ALMEIDA, Rafael. O governo Dilma Rousseff e a América do Sul: a atuação brasileira na UNASUL (2011-2014). Colombia Internacional, [s.l.], v. 92, p.43-72, 1 out. 2017. Universidad de los Andes.

GÓMEZ, Jacqueline del Rosario. Interelación y coexistencia entre la supranacionalidad e intergubernamentalidad en los procesos de integración. Cuadernos de Investigación Jurídica, Monagua, v. 2, n. 5, p. 1-46, out./dez. 2012.

GRASSI; Jéssica; CASA; Gabriela. A Unasul e os desafíos na institucionalização do espaço geopolítico sul-americano. Espirales, [s.l.], edição especial, p. 198-214, mai. 2019.

HAAS, Ernst. The uniting of Europe: Political, Social, and Economic Forces, 1950-1957. Stanford: Stanford University Press, 1958. 
HERZ, Monica; HOFFMANN, Andrea. Organizações Internacionais: história e práticas. Rio de Janeiro: Editora Campus, 2004

HOFFMANN, Andrea. As organizações regionais e a promoção e proteção da democracia: reflexões a partir das práticas de intervenção democrática na América do Sul. Caderno CRH, v. 29 , n. 3, p. 47-57, 2016

ITAMARATY. Reunião Extraordinária do Conselho de Chefas e Chefes de Estado e de Governo da UNASUL - Quito, 5 de dezembro de 2014. Brasília, 2014. Disponível em: http:// www.itamaraty.gov.br/pt-BR/notas-a-imprensa/6155-reuniao-extraordinaria-do-conselho-de-chefas-e-chefes-de-estado-e-de-governo-da-unasul-quito-5-de-dezembro-de-2014. Acesso em 25 mar. 2020

JAEGER, Bruna Coelho. Crise e colapso da UNASUL: o desmantelamento da integração sul-americana em tempos de ofensiva conservadora. Conjuntura Austral, [s.1.], v. 10, n. 49, p. 5, 4 abr. 2019.

JORNAL DO COMÉRCIO. Bolsonaro assina a Declaração de Santiago de criação do fórum Prosul. Jornal do Comércio, Porto Alegre, 22 mar. 2019. Disponível em: https://www.jornaldocomercio.com/_conteudo/galeria_de_imagens/2019/03/675931-bolsonaro-assina-a-declaracao-de-santiago-de-criacao-do-forum-prosul.html. Acesso em 03 mar. 2020.

LOMBAERDE, Philippe de; VAN LANGENHOVE, Luk. Indicators of regional integration: conceptual and methodological aspects. In: LOMBAERDE, Philippe de (Ed.). Assessment and measurement of regional integration. Abingdon: Routledge, 2006. p. 9-41. (Routledge/Warwick Studies in Globalisation).

LYRA, Mariana. A atuação da Unasul nas crises democráticas sul-americanas (2008- 2015). In: Congresso Latino Americano de Ciência Política, 9², 2017, Montevideo. Associação Latino-Americana de Ciência Política (ALACIP). Montevideo: Alacip, 2017.

MORAES, Marcelo Viana Estevão de. A política externa brasileira e a integração da América do Sul: o Brasil, a Unasul e a Coordenação de Governo. Revista de Políticas Públicas e Gestão Governamental, [s.1.], v. 14, n. 2, p.71-85, dez. 2015.

OLIVEIRA, Johidson André de. OEA e UNASUL: Transição de uma governança hemisférica para uma subemisférica?. 2017. 144 f. Dissertação (Mestrado) - Curso de Integração da América Latina, Prolam/usp, Usp, São Paulo, 2017.

PECEQUILO, Cristina Soreanu. A política externa do Brasil no século XXI: os eixos combinados de cooperação horizontal e vertical. Revista Brasileira de Política Internacional, [s.1.], v. 51, n. 2, p.136-156, dez. 2008.

PINCHEMEL, Elisa de Souza Ribeiro. Instituições e integração regional na América do Sul: uma análise comparativa entre Aladi, Mercosul e Unasul. 2016. 215 f. Tese (Doutorado) - Curso de Estudos Comparados Sobre As Américas, Instituto de Ciências Sociais, Unb, Brasília, 2016.

PINTO, Rafael. A ascensão e o definhamento da UNASUL: ontingência, trajetória e o protagonismo presidencial. 2019. 316 f. Tese (Doutorado) - Curso de Ciência Política, Ppgcp, Ufrgs, Porto Alegre, 2019.

SANTOS, Janine Macedo Vitorino dos. O projeto e a atuaçãodo Brasil como liderança regional. 2018. 77 f. Dissertação (Mestrado) - Curso de Relações Internacionais, Instituto de Economia e Relações Internacionais, Ufu, Uberlândia, 2018.

SENADO FEDERAL. Aprova o texto do Protocolo Adicional ao Tratado Constitutivo da UNASUL sobre Compromisso com a Democracia, assinado em Georgetown, em 26 de novembro de 2010. Disponível em: http://legis.senado.leg.br/sdleg-getter/documento?dm=5079280. Acesso em: 11 jun. 2020.

SENHORAS, Elói Martins. A regionalização transnacional na América do Sul e a institucionalização diplomática da Unasul. Núcleo Amazônico de Pesquisa em Relações internacionais (NAPRI), [s.l.], 2010. Disponível em: https://pdfs.semanticscholar.org/fff1/05f7f6cce7363c051e2964f0e7b61b173f18.pdf. Acesso em 10 set. 2019.

SERBIN, Andres. A América do Sul em um mundo multipolar: a Unasul é a alternativa? Nueva Sociedad, [s.l.], Buenos Aires, v. 1, n. 1, p.4-16, dez. 2009. Disponível em: http://nuso.org/media/ articles/downloads/p7-1_1.pdf. Acesso em: 29 set. 2019.

SPEKTOR, Matias. O projeto autonomista na política externa. In: Neto, A. Política externa, espaço e desenvolvimento. Brasília, IPEA, 2014.

SWEET, Alec; SANDHOLTZ, Wayne. Integration, supranational governance and the institutionalization of the European policy. In: SANDHOLTZ, Wayne; SWEET, Alec (Ed.). European integration and supranational governance. Oxford: Oxford University Press, 1998. Cap. 1. p. 1-26. 
QUEIROZ, Augusto. Paraguai diz ser necessário "redirecionar" objetivos da Unasul. Agência Brasil, [s.l.], 23 abr. 2018. Disponível em: https://agenciabrasil.ebc.com.br/internacional/noticia/2018-04/paraguai-diz-ser-necessario-redirecionar-objetivos-da-unasul. Acesso em: 03 abr. 2020.

TERRA. Grupo de Montevideo exige eleições na Venezuela. Terra Online, [s.l.], 07 fev. 2019. Disponível em: https://www.terra.com.br/noticias/mundo/grupo-de-montevideu-exige-eleicoes-na-venezuela,266177bc61a5c1e3efc737626b7db51b8kgpahyv.html. Acesso em: 03 mar. 2020.

TILLMAN, Kathrine. Why States Seek Membership in Supranational Institutions. 2015. $59 \mathrm{f}$. Tese (Doutorado) - Curso de Ciência Política, Department Of Political Science, Saint John's University, Nova York, 2015. Disponível em: http://digitalcommons.csbsju.edu/honors_theses/76. Acesso em: 7 ago. 2018.

UNASUL. Tratado Constitutivo da União de Nações Sul-Americanas, 2008. Disponível em: http://www.itamaraty.gov.br/images/ed_integracao/docs_UNASUL/TRAT_CONST_PORT. pdf. Acesso em: 23 set. 2019.

VASCONCELOS, Gabriel; CHIARETTI, Daniela. Desmate na Amazônia ameaça acordo com UE. Valor Econômico, [s.l.], 2020. Disponível em: https://valor.globo.com/brasil/noticia/2020/03/04/desmate-na-amazonia-ameaca-acordo-com-ue.ghtml. Acesso em: 27 mar. 2020.

VAZ, Alcides Costa. A crise venezuelana como fator de instabilidade regional: perspectivas sobre seu transbordamento nos espaços fronteiriços. Análise Estratégica, [s. l.], v. 3, n. 3, p. 1-7, fev. 2017.

VENTURA, Deisy; BARALDI, Camila. A Unasul e a nova gramática da integração sul-americana. Pontes, [s.l.], p.14-16, jul. 2008.

VERDROSS, Alfred. Derecho Internacional Público. 2. Ed. Madrid: Biblioteca Jurídica Aguilar, 1980 .

VIZENTINI, Paulo Fagundes. O G-3 e o G-20: o Brasil e as novas coalizões internacionais. In: ALTEMANI, Henrique; LESSA, Antônio (org.). Relações Internacionais do Brasil: temas e agendas. São Paulo: Saraiva, v. 2, 2006. 